\title{
O ADOECIMENTO DE ADULTOS POR CÂNCER E A REPERCUSSÃO NA FAMÍLIA: UMA REVISÃO DA LITERATURA
}

\author{
THE ILLNESS OF ADULTS BY CANCER AND THE IMPACT ON THE FAMILY: A LITERATURE REVIEW

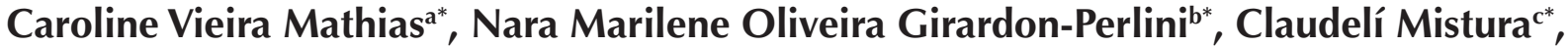 Caren da Silva Jacobi ${ }^{\mathrm{d}^{*}}$, Bruna Stamm ${ }^{\mathrm{e}^{*}}$}

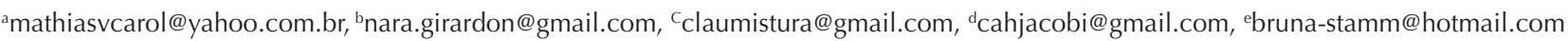
*Universidade Federal de Santa Maria - Santa Maria (RS), Brasil

Data de recebimento do artigo: 30/06/2014 Data de aceite do artigo: 30/01/2015

\section{RESUMO}

Introdução: $\mathrm{O}$ câncer acarreta alteraçôes na vida dos pacientes e de seus familiares, e sua família exerce significativa influência sobre a saúde, o bem-estar de cada um de seus membros e as enfermidades que os atingem. Objetivo: Identificar na literatura as produçóes científicas sobre a repercussão na família quando um de seus membros adulto adoece por câncer. Métodos: Estudo de revisão narrativa da literatura, realizado em junho de 2012, nas bases de dados da Literatura Latino-Americana e do Caribe em Ciências da Saúde (LILACS); Base de Dados de Enfermagem (BDENF) e Medical Literature Analysis and Retrieval System (MEDLINE), a partir dos descritores "família" or "relaçóes familiares" and "neoplasias". $\mathrm{O}$ corpus do estudo se constituiu de 16 artigos. Resultados: A repercussáo na família de ter um de seus membros adultos com câncer inicia-se com o diagnóstico da doença, causando sentimentos diversos, o que interfere de forma positiva ou negativa nas relaçóes familiares. Percebeu-se também que, de modo geral, após o diagnóstico de câncer, a união e o relacionamento entre os membros da família se tornaram mais consolidados, constituindo-se em fonte de apoio, segurança e estabilidade emocional. Conclusão: As repercussões negativas, como os sentimentos advindos da confirmação do diagnóstico, se configuram como possíveis causas para a falta de comunicação entre os membros da família. As repercussóes positivas, tais como a consolidação do relacionamento familiar e o apoio entre seus membros podem contribuir para a elaboração de estratégias, na tentativa de reorganizar e/ou manter a estrutura familiar.

Palavras-chave: Família; relaçôes familiares; neoplasias; enfermagem.

\section{ABSTRACT}

Introduction: Cancer changes the lives of patients and their families, and there is significant influence of the family on health, well-being of each member and on diseases that affect them. Objective: To identify in literature scientific papers about the impact on the family when one of its members falls ill adult cancer. Methods: A narrative review, conducted in June 2012, the databases of the Latin American and Caribbean Literature on Health Sciences (LILACS); Database of Nursing (BDENF), and Medical Literature Analysis and Retrieval System (MEDLINE), with the descriptors "família" or "relaçôes familiares" and "neoplasias". The corpus of the study consisted of 16 items. Results: The impact of having one of the adult members on a family with cancer begins with the diagnosis of the disease, causing many feelings, which interferes positively or negatively on family relationships. It was also felt that in general, after the cancer diagnosis, the union and the relationship between family members increases, becoming a source of support, security and emotional stability, which, in a way, collaborates to alleviate suffering. Conclusion: The negative effects, such as feelings arising of diagnostic confirmation, configure as possible causes for the lack of communication between family members. The positive repercussions, such as the consolidation of family relationship and support of members can contribute to the development of strategies to try to reorganize and keep the family structure.

Keywords: Family; family relations; neoplasms; nursing. 


\section{Introdução}

A família exerce influência significativa sobre a saúde e o bem-estar de cada um de seus membros, podendo interferir consideravelmente sobre as enfermidades que os atingem. Esse aspecto vem sendo evidenciado na teoria, na prática e nas pesquisas da enfermagem ${ }^{1}$. As doenças acometem o ser humano em qualquer faixa etária, e dependendo das características e do grau de ajustamento familiar anterior ao adoecimento, as consequências podem ser avassaladoras ${ }^{2}$.

O termo "família" pode ser entendido como uma unidade social que assume uma série de tarefas e responsabilidades, funcionando como matriz do desenvolvimento psicossocial de seus membros, e atendendo, ao longo do ciclo vital, à motivação básica do ser humano: a vida em conjunto. No entanto, sua estrutura e suas funçóes podem sofrer alteraçóes, dependendo das necessidades de cada pessoa, das experiências que elas vivenciam e do meio em que vivem ${ }^{3}$.

Em relação às alteraçóes familiares que podem ocorrer, o processo de adoecimento se torna um dos principais fatores de ajustamento familiar. $\mathrm{O}$ tratamento do câncer, especificamente, pode resultar em estresse imposto ao indivíduo previamente hígido, envolvendo um processo de adaptaçáo, havendo a possibilidade de desajustes psicológicos ${ }^{3}$ e familiares. Assim, a convivência com o câncer acarreta mais alteraçóes na vida dos pacientes e de sua família do que outras formas de doença, visto que dificilmente outra patologia induz a tantos sentimentos negativos em qualquer um dos seus estágios: o choque do diagnóstico, o medo da cirurgia, a incerteza do prognóstico e recorrência, os efeitos do tratamento, o medo da dor e o medo de encarar uma morte indigna ${ }^{4}$.

Nesse contexto, ter um membro da família com câncer pode contribuir para desestruturar a base familiar, pois gera sofrimento em todas as pessoas envolvidas. Isso acontece porque a família se configura como uma rede social de apoio, constituída por um grupo hierarquizado de pessoas que mantêm, entre si, laços e relações afetivas intensas 5 .

Considerando o câncer como uma doença que acarreta diversas transformaçôes físicas, psíquicas e sociais na vida dos indivíduos acometidos, se torna mister compreender também sua repercussão na vida da família, pois é a unidade primária de cuidado, um espaço social no qual seus membros interagem, trocam informaçóes e, ao identificar problemas de saúde, se apoiam mutuamente e envidam esforços na busca de soluçôes ${ }^{6}$. Desse modo, o presente estudo tem como questão de pesquisa: Que repercussão a existência de um membro adulto com câncer tem na família? No intuito de encontrar respostas para esse questionamento, traçou-se como objetivo identificar na literatura as produçóes científicas sobre essa repercussão.

\section{Metodologia}

Trata-se de um estudo de revisão da literatura, com abordagem qualitativa. A seleção dos artigos ocorreu em junho de 2012, nas seguintes bases de dados: Literatura da América Latina e Caribe em Ciências da Saúde (LILACS), Base de Dados em Enfermagem (BDENF) e Medical Literature Analysis and Retrieval System Online (MEDLINE), cujos descritores foram "família" or "relaçôes familiares" and "neoplasias".

Para ser incluído no corpus da pesquisa, o material bibliográfico precisava obedecer aos seguintes critérios de inclusão: ser artigo; ter texto completo disponível em suporte eletrônico, acesso gratuito e idioma português, inglês ou espanhol; atender ao objetivo do estudo e ser publicado após o ano 2005, uma vez que este é considerado um marco pela instituição da Política Nacional de Atenção Oncológica, que estabelece a promoção, a prevenção, o diagnóstico, o tratamento, a reabilitação e os cuidados paliativos como competências das três esferas de governo. Excluíram-se da seleção os artigos que tinham apenas o resumo disponível on-line.

Foram encontrados 1.980 artigos, sendo 1.874 indexados na MEDLINE, 74 na LILACS e 32 na BDENF. Cabe ressaltar que alguns artigos se repetiam. Diante dos critérios de inclusão e após leitura dos títulos e resumos, foram selecionados 16 artigos para a constituição do corpus deste estudo.

A análise dos dados se iniciou com a leitura criteriosa dos títulos, resumos e conteúdo dos artigos. Posteriormente, os artigos foram catalogados em um quadro e organizados por autores, título, objetivo, procedência do estudo, ano, área de conhecimento, delineamento do estudo e conclusóes.

A análise dos dados extraídos foi realizada na forma descritiva. Essa sondagem não fornece apenas subsídios na tomada de decisão da enfermagem em relação à família que possui um membro adulto com câncer, mas também na identificação de lacunas na produção de conhecimentos nessa área, incentivando o desenvolvimento de futuras pesquisas.

\section{Resultados e discussão}

Considerando o objetivo do estudo e os artigos analisados (Tabela 1$)^{7-22}$, a classificação dos artigos de abordagem qualitativa (11) predominou em relação aos de abordagem quantitativa (5). Quanto à procedência das 
publicaçóes, verificou-se que os estudos foram desenvolvidos predominantemente no Brasil (12), especificamente na regiáo sul (5), nordeste (3), sudeste (3) e centro-oeste (1). Já nos Estados Unidos da América foram realizados 3 estudos, e no Chile 1 . O maior número de publicaçóes (5) ocorreu no ano 2010, seguido dos anos 2009 (3), e por último, 2005, 2006, 2007 e 2008 (2 por ano).

Encontraram-se 14 produçóes de enfermagem publicadas em periódicos especializados. A medicina também se destacou, com 4 artigos publicados em periódicos de Cancerologia e Ciências da Saúde.

Tabela 1: Identificação dos estudos que compõem a revisão da literatura.

\begin{tabular}{|c|c|}
\hline Código & Referência \\
\hline$A^{7}$ & $\begin{array}{l}\text { Araújo LZS et al. Cuidador principal de paciente oncológico fora de possibilidade de cura, repercussóes desse encargo. Rev } \\
\text { Bras Enferm. 2009;62(1):32-7. }\end{array}$ \\
\hline$A^{8}$ & $\begin{array}{l}\text { Ashida } S \text { et al. The impact of familial environment on depression scores after genetic testing for cancer susceptibility. Clin } \\
\text { Genet. 2009;75(1):43-9. }\end{array}$ \\
\hline $\mathrm{A}^{9}$ & $\begin{array}{l}\text { Barreto TS, Amorim RC. A família frente ao adoecer e ao tratamento de um familiar com câncer. Rev Enferm UERJ. } \\
\text { 2010;18(3):462-7. }\end{array}$ \\
\hline $\mathrm{A}^{10}$ & $\begin{array}{l}\text { Barros DO, Lopes RLM. Mulheres com câncer invasivo do colo uterino: suporte familiar como auxílio. Rev Bras Enferm. } \\
\text { 2007;60(3):295-8. }\end{array}$ \\
\hline $\mathrm{A}^{11}$ & $\begin{array}{l}\text { Biffi RG, Mamede MV. Dinâmica familiar: percepçâo de famílias de sobreviventes de câncer de mama. Esc Anna Nery Rev } \\
\text { Enferm. 2009;13(1):131-9. }\end{array}$ \\
\hline $\mathrm{A}^{12}$ & $\begin{array}{l}\text { Biffi RG, Mamede MV. Percepção do funcionamento familiar entre familiares de mulheres sobreviventes ao câncer de } \\
\text { mama: diferenças de gênero. Rev Latino-Am Enferm. 2010;18(2):[09 telas]. }\end{array}$ \\
\hline $\mathrm{A}^{13}$ & Jones RA et al. Family interactions among african american prostate cancer. Fam Community Health. 2008;31(3):213-20. \\
\hline $\mathrm{A}^{14}$ & $\begin{array}{l}\text { Maruyama SAT, Zago MMF. O processo de adoecer do portador de colostomia por câncer. Rev Latino-Am Enferm. } \\
\text { 2005;13(2):216-22. }\end{array}$ \\
\hline $\mathrm{A}^{15}$ & $\begin{array}{l}\text { Molina MASA, Marconi SS. Mudanças nos relacionamentos com os amigos, cônjuge e família após o diagnóstico de câncer } \\
\text { na mulher. Rev Bras Enferm. 2006;59(4):514-20. }\end{array}$ \\
\hline $\mathrm{A}^{16}$ & Salci MA, Marcon SS. A convivência com o fantasma do câncer. Rev Gaúcha Enferm. 2010;31(1):18-25. \\
\hline $\mathrm{A}^{17}$ & $\begin{array}{l}\text { Salci MA, Marcon SS. Itinerário percorrido pelas mulheres na descoberta do câncer. Esc Anna Nery Rev Enferm. } \\
\text { 2009;13(3):558-66. }\end{array}$ \\
\hline $\mathrm{A}^{18}$ & $\begin{array}{l}\text { Silva CAM, Acker JIBV. O cuidado paliativo domiciliar sob a ótica de familiares responsáveis pela pessoa portadora de } \\
\text { neoplasia. Rev Bras Enferm. 2007;60(2):150-4. }\end{array}$ \\
\hline $\mathrm{A}^{19}$ & $\begin{array}{l}\text { Simino GPR, Santos CB, Mishima SM. Acompanhamento de usuários, portadores de câncer, por trabalhadores da saúde } \\
\text { da família. Rev Latino-Am Enferm. 2010;18(5):[09 telas]. }\end{array}$ \\
\hline $\mathrm{A}^{20}$ & $\begin{array}{l}\text { Snyder KA, Pearse W. Crisis, social support, and the family response: exploring the narratives of young breast cancer survi- } \\
\text { vors. J Psychosoc Oncol. 2010;28(4):413-31. }\end{array}$ \\
\hline $\mathrm{A}^{21}$ & $\begin{array}{l}\text { Venegas ME, Alvarado OS. Fatores relacionados à qualidade do processo de morrer na pessoa com câncer. Rev Latino-Am. } \\
\text { Enfermagem. 2010;18(4):[08 telas]. }\end{array}$ \\
\hline $\mathrm{A}^{22}$ & $\begin{array}{l}\text { Vieira MCU, Marcon SS. Significados do processo de adoecer: o que pensam cuidadoras principais de idosos portadores de } \\
\text { câncer. Rev Esc Enferm USP. 2008;42(4):752-60. }\end{array}$ \\
\hline
\end{tabular}

A partir da análise dos artigos, emergiram três categorias: a família diante do diagnóstico de câncer, repercussóes positivas do câncer no contexto familiar e repercussóes negativas do câncer no contexto familiar. Elas serão apresentadas e discutidas a seguir.

\section{A família diante do diagnóstico de câncer}

Alguns artigos evidenciaram que a repercussão na família de ter um de seus membros adultos com câncer se inicia já no diagnóstico da doença. Esse é um momento acompanhado de intensas alteraçóes físicas, emocionais e sociais, tanto para o paciente, quanto para seus familiares, visto que ocorre o compartilhamento da experiência de vivenciar essa patologia ${ }^{7-10}$.

O diagnóstico do câncer, ou a simples possibilidade de sua confirmação, rompe com o equilíbrio individual e familiar. Mesmo diante dos avanços científicos e tecnológicos na área da oncologia, a associação do diagnóstico de câncer com a morte está táo arraigada culturalmente, que sua marca permanece nas pessoas ${ }^{23}$.

Diante dessa realidade, emerge uma diversidade de sentimentos que colocam a família em dilema devido 
ao adoecimento de seu ente querido, e ao impacto no contexto familiar, tornando necessária a reelaboração de conceitos e a adaptaçáo à nova realidade ${ }^{11,12}$. A pessoa doente e sua família precisam de certo tempo para a assimilaçáo, processamento e elaboraçáo do dado novo: a doença ${ }^{24}$.

Considera-se que uma unidade familiar está em equilíbrio quando cada membro está interagindo e desempenhando seu papel com eficiência, conforme as demandas do período vivenciado. No momento de ruptura desse equilíbrio e de ameaça a sua homeostase, a família que se encontra disfuncional precisa responder às exigências externas e internas das mudanças ${ }^{23}$.

Em complemento, outras publicaçóes abordam o câncer como uma doença familiar, não sob o ponto de vista genético, mas tendo em vista o impacto provocado. Quando um membro da família é diagnosticado, todos os familiares são afetados em maior ou menor grau ${ }^{12}$. Por consequência, o envolvimento prático e emocional na jornada do paciente com câncer (diagnóstico, tratamento, recidivas da doença etc.) afeta a vida da família, às vezes de modo profundo, podendo repercutir de forma positiva ou negativa no contexto familiar ${ }^{13,14}$.

Nas famílias que vivenciam o câncer, cada membro reage de maneira diferente conforme sua estrutura interna ${ }^{24}$. Dessa forma, a assistência deve estar voltada à unidade familiar inteira, observando, sobretudo, sua interação, uma vez que esse tipo de observação permite a avaliação dos relacionamentos existentes entre os membros familiares, assim como o comportamento particular de cada um deles ${ }^{1 .}$

\section{Repercussões positivas do câncer no contexto familiar}

De modo geral, após o diagnóstico de câncer, a união e o relacionamento entre os membros da família se tornaram mais consolidados, constituindo-se uma fonte de apoio, segurança e estabilidade emocional, que de certa forma colabora para amenizar o sofrimento ${ }^{8,15}$. Em geral, toda a família se mobiliza para acolher, confortar, cuidar e acompanhar o familiar em sua trajetória de adoecimento ${ }^{16,12}$.

Diante da doença, a comunicação clara é uma das estratégias usadas para buscar o equilíbrio do funcionamento familiar, aliviando a tensão e favorecendo a interação ${ }^{8,12}$. Dessa forma, todos buscam, juntos, novas informaçôes sobre o câncer, sobre a disponibilidade de tratamentos e sobre seus possíveis efeitos colaterais ${ }^{17}$.

O envolvimento da família é essencial em qualquer momento do adoecimento por câncer, especialmente para assegurar a adesão ao tratamento e prover suporte emocional. É próprio da família vivenciar problemas e crises em seu cotidiano. Contudo, uma família com boa interação, comunicação aberta e flexibilidade entre os membros contribui para a soluçáo de problemas e para enfrentar possíveis conflitos ${ }^{25}$.

Destacou-se o predomínio de publicaçóes relacionadas ao adoecimento por câncer de mama e sua repercussão na família. Alguns artigos indicaram que a partir do diagnóstico de câncer de mama, por exemplo, o marido se torna mais próximo da esposa, manifestando solicitude, compreensão, atenção e acolhimento a ela, melhorando o relacionamento diário, o vínculo afetivo e a vida íntima do casal ${ }^{15,12}$. A doença oferece oportunidade à reavaliação de sentimentos e posturas dentro da relação conjugal. Muitas vezes, a recuperação da mulher está relacionada à forma como o companheiro lida com a situação, o que torna evidente a importância do apoio do parceiro de forma integral ${ }^{26}$, pois mulheres com câncer de mama que recebem apoio familiar apresentam diminuição do sofrimento psicológico e maior estabilidade emocional ${ }^{27}$.

Além disso, os filhos demonstram maior envolvimento para dar suporte à mãe. Muitas vezes, mesmo não estando preparados, mas talvez movidos pelo medo de perder a mãe, eles acabam assumindo papéis importantes, como ajudar nas atividades ou tarefas do $\operatorname{lar}^{16}$. Nesse contexto, eles se sentem como pessoas que experimentam suas identidades pessoais nos relacionamentos familiares, e que diante dos problemas, criam estratégias de enfrentamento, procurando ajudar, como fazem os demais membros da unidade familiar ${ }^{13,10}$.

$\mathrm{Na}$ maioria dos casos, a possibilidade de perda da mãe leva os filhos a se reorganizarem, modificarem comportamentos e atitudes, a fim de fortalecê-la e apoiá-la. Embora sintam medo, procuram expressar palavras de ânimo, coragem e incentivo. Essas atitudes, aliadas à ajuda nos afazeres domésticos, às manifestaçôes de carinho e à participação ativa no tratamento, contribuem positivamente para a autoaceitação feminina ${ }^{28}$.

Pode ocorrer, ainda, a aproximação de familiares distantes, porque eles percebem o sofrimento da mulher e também sofrem com ela. Pelo medo do que o futuro lhes reserva, assumem, então, uma postura de autocobrança, e buscam oferecer suporte emocional por meio da companhia, ligaçóes telefônicas e/ou visitas mais frequentes ${ }^{10,15,17}$.

Já em relaçáo ao câncer no homem e à sua repercussão na família, um artigo abordou que, em caso de câncer de próstata, as esposas não identificam mudanças significativas no papel de seu marido, mesmo quando há sintomas da doença (incontinência e impotência). Essas mulheres não faziam da relação sexual o único caminho para a intimidade, encontrando outras formas de expressarem seu amor pelo marido?.

Quando se leva em conta o impacto do câncer de próstata sobre a vivência da sexualidade e a construção 
da masculinidade para os homens afetados, o enfrentamento da doença lhes determina uma reconfiguração das noçóes de sexualidade ${ }^{29}$. Parte desse enfrentamento inclui a reconfiguração da relação conjugal e a criação de uma nova identidade social.

\section{Repercussões negativas do câncer no contexto familiar}

Após o diagnóstico de câncer, muitas vezes, ao perceber que seu ente querido pode deixar de estar próximo, a família tende a ignorar ou negar o fato em si, ou seja, não conversa sobre a doença e, inconscientemente, ao acreditar na negação, não cogita a possibilidade da perda $^{13}$. Isso pode estar relacionado com os sentimentos advindos da confirmação do diagnóstico, como tristeza, frustração, angústia, dificuldade de introjeção, aceitação e apreensão, que se configuram como possíveis causas para a falta de comunicação entre os membros da família e para a ausência de apoio, levando ao isolamento gradual do familiar doente ${ }^{18,10}$. Nesse sentido, o padrão de comunicação entre os familiares tem influência significativa no processo de adaptação da família à doença ${ }^{25}$.

Outro aspecto abordado nas publicaçóes dessa revisão diz respeito ao familiar acometido pelo câncer, que necessita, com frequência, de um responsável para auxiliá-lo nas tarefas cotidianas. Assim, a mulher (mãe, esposa, avó ou tia) emerge como figura principal no ato de prestar esses cuidados, ainda que, muitas vezes, ela náo tenha optado por isso, e até mesmo não se reconheça como cuidadora ${ }^{11,14,19,20}$. Isso ocorre na atualidade, quando observado o incentivo para que a família assuma a responsabilidade de cuidar do familiar doente, mesmo em situaçóes que envolvam cuidados de certa complexidade, especialmente quando a doença está em curso avançado ${ }^{30}$.

Essa situação pode gerar sobrecarga à família, devido ao aumento da demanda de atividades diárias e ininterruptas, principalmente pelo comprometimento psicossocial na vida daqueles envolvidos nos cuidados, que podem apresentar depressão, tristeza, distúrbios do sono, nutrição precária, medo, maior uso de psicoterápicos, rupturas de vínculo, conflito de papéis, isolamento, solidão, diminuição da participação social, erosão nos relacionamentos, perda do suporte social e menor satisfação com a vida ${ }^{7,11,22,24}$. Outro agravante que pode acometer os membros da família é a sobrecarga econômica, que emerge como um significativo fator de estresse. As famílias de pacientes com alto grau de dependência são as mais atingidas financeiramente ${ }^{15,22}$.

Os familiares que cuidam de pacientes com câncer se sentem sobrecarregados com o tempo empregado nas atividades também, pois se esforçam para cuidar do familiar doente, assumem tarefas domésticas, responsabilidades financeiras, e suportam as modificaçóes da rotina familiar impostas pelo processo terapêutico, enquanto tentam suprir suas próprias necessidades e manter uma rotina familiar normal ${ }^{30}$.

Em relação ao câncer na mulher, alguns estudos evidenciam que o câncer de mama foi o principal diagnóstico a influenciar de maneira negativa a vida conjugal, sendo a interferência ainda mais intensa quando a relação já estava abalada anteriormente. A desestruturaçâo se torna ainda maior e pode culminar com a traição conjugal por parte do marido, em mudanças na vida sexual do casal, na separação matrimonial, no refúgio do marido na bebida, no cigarro e na ausência em casa na maior parte do dia $^{8,15}$. Isso ocorre porque, com o adoecimento, a mulher geralmente fica mais debilitada para seu papel de cuidadora do lar, além de fragilizar seu papel de esposa, exigindo mais paciência do marido. $\mathrm{O}$ tratamento quimioterápico, por sua vez, demanda mudanças na anticoncepção utilizada pelo casal, que pode diminuir a frequência das relaçóes sexuais ${ }^{8}$.

De igual forma, um estudo revelou que o câncer de próstata pode resultar em sequelas psicossociais, tais como: ansiedade em lugares públicos, devido à perda do controle urinário, impotência, e senso de masculinidade prejudicado pelo tratamento. Esses efeitos colaterais causaram transtornos na vida conjugal e sexual diária do casal'.

Com isso, a ocorrência do câncer de próstata pode influenciar na relação conjugal do casal, especialmente na sexualidade, uma vez que o homem tem sua vida modificada nas dimensôes física, social e psíquica ${ }^{29}$. Desse modo, durante o percurso da doença, é importante que ocorra a reabilitação psicossocial desses pacientes.

\section{Conclusão}

A partir desse estudo de revisão narrativa, demonstrou-se que a repercussão na família em ter um de seus membros adultos com câncer se inicia com o diagnóstico da doença, suscitando diversos sentimentos que podem refletir positiva ou negativamente, tanto no paciente como nos demais membros familiares. Essas repercussóes influenciam no modo como a família se organizará e funcionará diante do processo de adoecimento e tratamento.

Dentre as repercussôes positivas, apontaram-se: a consolidação do relacionamento familiar; o apoio e o carinho do marido, dos filhos e dos familiares nos casos de mulheres com câncer de mama; e a reconfiguração da vida íntima e da sexualidade masculina, pautada na compreensão da esposa, nos casos de câncer de próstata. Já entre as repercussões negativas, destacaram-se: a negaçáo da família ao diagnóstico de câncer; a sobrecarga física, emocional e financeira para a família e, muitas vezes, para um familiar em particular, já que a mulher 
é a principal responsável pelos cuidados; e ainda a desestruturação da relação conjugal, principalmente nos casos de câncer de mama e de próstata.

Evidenciou-se, ainda, a limitação nas publicaçóes relativas à repercussáo na família quanto ao diagnóstico de câncer em homens. A conduçáa de investigaçôes que abordem o contexto do adoecimento masculino por câncer pode contribuir para oferecer maior visibilidade aos aspectos da saúde do homem, e para subsidiar açôes efetivas de apoio, tanto ao homem acometido, como à sua família.

Aconselha-se que novas pesquisas sejam desenvolvidas sobre a repercussão de ter, na família, um membro adulto com câncer, possibilitando a reformulação das práxis de enfermagem no redirecionamento dessas ações, contribuindo para um cuidado efetivo a esse estrato populacional. Em síntese, o diagnóstico e o tratamento do câncer causam diversas repercussōes na vida das pessoas envolvidas, podendo modificar a dinâmica e o contexto de vida do paciente e de toda a sua família. Conclui-se que o câncer não repercute apenas na vida do paciente, mas também na de seus familiares, determinando os modos de enfrentamento da doença e de sua recuperação.

\section{Referências}

1. Wright L, Leahey M. Enfermeiras e famílias. Guia de avaliação e intervenção na família. 5a ed. São Paulo: Roca; 2012.

2. Silva FAC, Andrade PR, Barbosa TR, Hoffman MV, Macedo CR. Representação do processo de adoecimento de crianças e adolescentes oncológicos junto aos familiares. Esc Anna Nery Rev Enferm. Abr/jun 2009;13(2):334-41.

3. Gutierrez DMD, Minayo MCS. Produção de conhecimento sobre cuidados da saúde no âmbito da família. Ciênc Saúde Coletiva. 2010;15(1):1497-508.

4. Cheron MFL, Pettengill MAM. Experiência do irmão sadio em relação à doença e hospitalização do irmão com câncer. Acta Paul Enferm. 2011;24(5):605-10.

5. Montezuma CA, Freitas MC, Monteiro ARM. A família e o cuidado ao idoso dependente: estudo de caso. Rev Eletrôn de Enferm. 2008;10(2):395-404.

6. Souza MGG, Santo FHE. O olhar que olha o outro... Um estudo com familiares de pessoas em quimioterapia antineoplásica. Rev Bras de Cancerologia. 2008;54(1):31-41.

7. Barreto TS, Amorim RC. A família frente ao adoecer e ao tratamento de um familiar com câncer. Rev Enferm UERJ. 2010;18(3):462-7.

8. Biffi RG, Mamede MV. Dinâmica familiar: percepção de famílias de sobreviventes de câncer de mama. Esc Anna Nery Rev Enferm. 2009;13(1):131-9.

9. Jones RA, et al. Family interactions among african american prostate cancer. Fam Community Health. 2008;31(3):213-20.
10. Salci MA, Marcon SS. Itinerário percorrido pelas mulheres na descoberta do câncer. Esc Anna Nery Rev Enferm. 2009;13(3):558-66.

11. Araújo LZS, et al. Cuidador principal de paciente oncológico fora de possibilidade de cura, repercussóes deste encargo. Rev Bras Enferm. 2009;62(1):32-7.

12. Vieira MCU, Marcon SS. Significados do processo de adoecer: o que pensam cuidadoras principais de idosos portadores de câncer. Rev Esc Enferm USP. 2008;42(4):752-60.

13. Biffi RG, Mamede MV. Percepção do funcionamento familiar entre familiares de mulheres sobreviventes ao câncer de mama: diferenças de gênero. Rev Latino-Am Enferm. 2010;18(2):[09 telas].

14. Maruyama SAT, Zago MMF. O processo de adoecer do portador de colostomia por câncer. Rev Latino-Am Enferm. 2005;13(2):216-22.

15. Molina MASA, Marconi SS. Mudanças nos relacionamentos com os amigos, cônjuge e família após o diagnóstico de câncer na mulher. Rev Bras Enferm. 2006;59(4):514-20.

16. Venegas ME, Alvarado OS. Fatores relacionados à qualidade do processo de morrer na pessoa com câncer. Rev LatinoAm Enferm. 2010;18(4):[08 telas].

17. Snyder KA, Pearse W. Crisis, social support, and the family response: exploring the narratives of young breast cancer survivors. J Psychosoc Oncol. 2010;28(4):413-31.

18. Barros DO, Lopes RLM. Mulheres com câncer invasivo do colo uterino: suporte familiar como auxílio. Rev Bras Enferm. 2007;60(3):295-8.

19. Ashida $S$, et al. The impact of familial environment on depression scores after genetic testing for cancer susceptibility. Clin Genet. 2009;75(1):43-9.

20. Simino GPR, Santos CB, Mishima SM. Acompanhamento de usuários, portadores de câncer, por trabalhadores da saúde da família. Rev Latino-Am Enferm. 2010;18(5):[09 telas].

21. Salci MA, Marcon SS. A convivência com o fantasma do câncer. Rev Gaúcha Enferm. 2010;31(1):18-25.

22. Silva CAM, Acker JIBV. O cuidado paliativo domiciliar sob a ótica de familiares responsáveis pela pessoa portadora de neoplasia. Rev Bras Enferm. 2007;60(2):150-4.

23. Gomes CHR, Silva PV, Motta FF. Comunicação do diagnóstico de câncer: análise do comportamento médico. Rev Bras de Cancerologia. 2009;55(2):139-43.

24. Bossoni RHC, Stumm EMF, Hildebrand LM, Loro MM. Câncer e morte: um dilema para pacientes e familiares. Rev Cont \& Saúde. 2009;9(17):13-21.

25. Black K, Lobo M. A conceptual review of family resilience factors. J Fam Nurs. 2008;14(1):33-55.

26. Ferreira DB, Farago PM, Reis PED, Funghetto SS. Nossa vida após o câncer de mama: percepções e repercussóes sob o olhar do casal. Rev Bras Enferm. 2011;64(3):536-44.

27. Silva VR, Gradim CVC. Avaliação da dor em mulheres com câncer de mama submetidas à exérese da rede linfática axilar. Cogitare Enferm. 2010;15(4):646-51.

28. Vasconcelos PM, Neves JB. Importância do apoio familiar à mulher submetida à cirurgia para tratamento 
da neoplasia mamária. Rev Enferm Integ - Ipatinga. 2010;3(1):422-32.

29. Moscheta MS, Santos M. A. Grupos de apoio para homens com câncer de próstata: revisão integrativa da literatura. Ciênc Saúde Coletiva. 2012;17(5):1225-33.
30. Araújo LZS, Araújo CZS, Souto AKBA, Oliveira MS. Cuidador principal de paciente oncológico fora de possibilidade de cura, repercussóes deste encargo. Rev Bras Enferm. 2009;62(1):32-7. 